\title{
Ornithine Decarboxylase Activity and Polyamine Content during Zoospore Germination and Hormone-induced Sexual Differentiation of Achlya ambisexualis
}

\author{
By JONATHAN M. WRIGHT, WAYNE P. GULLIVER, \\ C. J. MICHALSKI AND STEPHEN M. BOYLE* \\ Faculty of Medicine, Memorial University of Newfoundland, St John's, \\ Newfoundland A1B 3V6, Canada
}

(Received 23 June 1981; revised 26 October 1981)

\begin{abstract}
The activity of ornithine decarboxylase (EC 4.1.1.17) and the intracellular pools of putrescine and spermidine were determined during zoospore germination and hormoneinduced sexual morphogenesis in Achlya ambisexualis. The specific activity of ornithine decarboxylase increased approximately 6 -fold during zoospore germination and outgrowth in an enriched medium. Ornithine decarboxylase activity exhibited a rapid and transient $5 \cdot 2$-fold increase during hormone-induced differentiation of mycelium cultured in enriched media. In contrast, the enzyme activity did not increase following hormone treatment of mycelium cultured in a minimal medium, yet mycelial differentiation occurred normally. Fluctuations in intracellular concentrations of putrescine and spermidine, in general, correlated with changes in ornithine decarboxylase activity during hormone-induced differentiation and zoospore germination.
\end{abstract}

\section{INTRODUCTION}

The water mould Achlya ambisexualis is perhaps the most primitive eukaryote that responds to steroid hormones (Barksdale, 1969). The female strains of Achlya constitutively secrete the sterol antheridiol, which induces the formation of sexual reproductive structures on the male thallus. The first morphological change following hormone treatment is the production of numerous antheridial initials which can be readily viewed by light microscopy. In addition to stimulating antheridial branch formation, antheridiol stimulates the synthesis of total RNA and poly(A)-containing RNA (Silver \& Horgen, 1974; Horgen et al., 1975; Timberlake, 1976) and a sequential increase in the rates of synthesis of three classes of proteins (Michalski, 1978). The rate of ribosomal protein synthesis increases as early as 20-30 min, followed by ribosomal salt-wash proteins at $40-60 \mathrm{~min}$ and total proteins after $60 \mathrm{~min}$. The enzyme cellulase, which is involved in cell wall softening at sites of antheridial branch formation, is also activated following hormone treatment (Thomas \& Mullins, 1967, 1969). During germination and outgrowth of asexual spores of Achlya there is a similar period of biochemical and morphological change in which the rate of RNA and protein synthesis increases (MacLeod \& Horgen, 1979).

Frequently associated with hormone-induced differentiation and rapid cellular proliferation is the accumulation of the polyamines, putrescine and spermidine, as well as an increase in the activity and rate of synthesis of their biosynthetic enzymes. In particular, an increase in ornithine decarboxylase (EC 4.1 .1 .17 ) activity, the first and probably rate-limiting enzyme in the polyamine biosynthetic pathway, precedes or parallels an increase in the rates of macromolecular synthesis (Tabor \& Tabor, 1976; Janne et al., 1978). 
In this paper we report the induction of ornithine decarboxylase activity during zoospore germination and hormone-induced sexual differentiation of the mycelium of Achlya ambisexualis. The induction of ornithine decarboxylase in hormone-treated mycelium was found to be dependent on the growth medium, whereas sexual differentiation was not. Fluctuations in intracellular pools of putrescine and spermidine, in general, correlated with changes in ornithine decarboxylase activity during hormone-induced mycelial differentiation and zoospore germination.

\section{METHODS}

Achlya ambisexualis (male strain E87 and female strain 734) was supplied by $\mathrm{Dr}$ W. E. Timberlake. Synthetic antheridiol was a generous gift from Dr T. McMorris. DL-[1-1 $\left.{ }^{14} \mathrm{C}\right]$ Ornithine $\left(49 \mathrm{mCi} \mathrm{mmol}{ }^{-1}, 1.81 \mathrm{GBq} \mathrm{mmol}^{-1}\right)$ and Protosol were purchased from New England Nuclear. All other chemicals were of reagent grade.

Culture maintenance and growth. Achlya ambisexualis male strain E87 and female strain 734 were used throughout this study. Stock cultures were maintained on Emerson's (1958) YpSs agar and subcultured on PYG $(1.25 \mathrm{~g}$ yeast extract, $1.25 \mathrm{~g}$ peptone, $3.0 \mathrm{~g}$ glucose per litre distilled water) agar plates for spore preparation according to the method of Griffin \& Breuker (1969). Spore cysts were stored in $0.5 \mathrm{mM}-\mathrm{CaCl}_{2}$ at $4{ }^{\circ} \mathrm{C}$ and used within $48 \mathrm{~h}$ of preparation.

Hormone induction. Liquid PYG medium was inoculated with approximately 2-3 $\times 10^{5}$ viable spores $\mathrm{ml}^{-1}$ (strain E87) and grown overnight at $28^{\circ} \mathrm{C}$ on a gyratory shaker at $150 \mathrm{rev} \cdot \mathrm{min}^{-1}$. A suspension of this culture was added at a dilution of $1: 10$ to one of the following induction media: PYG broth, Emerson's medium and M-1 minimal medium [L-glutamic acid, monopotassium salt, $2.6 \mathrm{mM}$; D-glucose, $16 \mathrm{mM}$; Tris, $10 \mathrm{mM}$; L-methionine, $0.1 \mathrm{mM} ; \mathrm{KCl}, 20 \mathrm{mM} ; \mathrm{CaCl}_{2}, 0.5 \mathrm{mM} ; \mathrm{KH}_{2} \mathrm{PO}_{4}, 1.5 \mathrm{mM} ; \mathrm{FeSO}_{4}, 4.5 \mu \mathrm{M}$; EDTA, $5.0 \mu \mathrm{M} ; \mathrm{MgSO}_{4}, 0.5 \mu \mathrm{M}$; micronutrients, according to Griffin et al. (1974) - the $\mathrm{pH}$ of the medium was brought to 6.9 with $\mathrm{HCl}$ prior to autoclaving]. Cultures $(2.5 \mathrm{l})$ were incubated at $28^{\circ} \mathrm{C}$ on a gyratory shaker $\left(150 \mathrm{rev}\right.$. $\left.\mathrm{min}^{-1}\right)$ for $17-18 \mathrm{~h}$. At this time the culture was divided into two equal aliquots and synthetic antheridiol, dissolved in methanol, was added to one aliquot at a final concentration of $1 \mathrm{ng} \mathrm{ml}^{-1}$. An equal volume of methanol was added to the control culture. After the addition of hormone, incubation at $28^{\circ} \mathrm{C}$ with shaking was continued. At timed intervals $200 \mathrm{ml}$ samples of culture were harvested by filtration, the mycelium was washed with 2 vol. growth medium at room temperature and resuspended in breakage buffer $\left[0.05 \mathrm{M}\right.$-Hepes ( $N$-2-hydroxyethylpiperazine- $N^{\prime}$-2-ethanesulphonic acid) pH 7.4, 0.33 M-sucrose, $10 \mathrm{~mm}$ - $\beta$-mercaptoethanol, $0.2 \mathrm{~mm}$-pyridoxal phosphate, $0.2 \mathrm{~mm}$-EDTA]. Crude lysates were prepared by gently homogenizing the mycelium and sedimenting the unbroken hyphae and cell wall debris by centrifugation at $15000 \mathrm{~g}$ for $10 \mathrm{~min}$.

Spore germination and outgrowth. Approximately $2-3 \times 10^{7}$ viable spores (strain E87 or strain 734 ) were used as an inoculum for a 21 culture in PYG broth. Incubation was at $28^{\circ} \mathrm{C}$ in a gyratory water bath. At timed intervals samples of the culture were removed and germinating spores were harvested by centrifugation. The pellet was washed with PYG broth at room temperature and then frozen in liquid nitrogen. The frozen pellet was ground with a mortar and pestle to a fine powder and the powder was dissolved in breakage buffer. The crude lysate was centrifuged at $15000 \mathrm{~g}$ for $10 \mathrm{~min}$ to sediment the cell wall debris and unbroken spore cysts.

Ornithine decarboxylase assay. Ornithine decarboxylase activity was assayed in crude extracts by measuring the release of ${ }^{14} \mathrm{CO}_{2}$ from DL-[1-1 $\left.{ }^{14} \mathrm{C}\right]$ ornithine. The assay mixture contained $0 \cdot 1 \mathrm{M}$-Hepes $\mathrm{pH} 7 \cdot 4,0.2 \mathrm{mM}$-EDTA, $0.67 \mu \mathrm{Ci}\left[{ }^{14} \mathrm{C}\right.$ lornithine $\mathrm{ml}^{-1}, 1.48 \mathrm{~mm}$-ornithine, $0.2 \mathrm{~mm}$-pyridoxal phosphate and $2.0 \mathrm{~mm}$-dithiothreitol; $190 \mu \mathrm{l}$ crude extract was added to the assay mixture to give a final volume of $300 \mu$. The reaction was started by placing the reaction vessel in a water bath at $37^{\circ} \mathrm{C}$. Release of $\mathrm{CO}_{2}$ was linear for more than $90 \mathrm{~min}$ and assays were routinely conducted for $60 \mathrm{~min}$. Trichloroacetic acid was added to a final concentration of $5 \%(\mathrm{w} / \mathrm{v})$ to terminate the reaction and convert $\mathrm{H}^{14} \mathrm{CO}_{3}^{-}$to free ${ }^{14} \mathrm{CO}_{2}$. The ${ }^{14} \mathrm{CO}_{2}$ was trapped in filter papers saturated with Protosol (placed in a plastic centre well) and determined by liquid scintillation spectrometry. The enzyme activity was expressed as nmol $\mathrm{CO}_{2}$ released $\mathrm{h}^{-1}$ (mg protein) $)^{-1}$, calculated from the specific activity of the L-isomer of ornithine in the assay mixture. The concentration of protein in the extracts was determined by the method of Schaffner \& Weissman (1973).

Cation concentrations in PYG and M-1 media. Calcium and magnesium concentrations in PYG and M-1 media were determined by atomic absorption spectrophotometry. Potassium and sodium concentrations were determined utilizing the flame emission mode of a Perkin-Elmer 360 atomic absorption spectrophotometer.

Polyamine analysis. Intracellular pools of putrescine and spermidine were determined according to Boyle et al. (1977) utilizing a Beckman Amino Acid Analyzer (model 121). Concentrations of the polyamines were normalized to the amount of protein in the extract. 


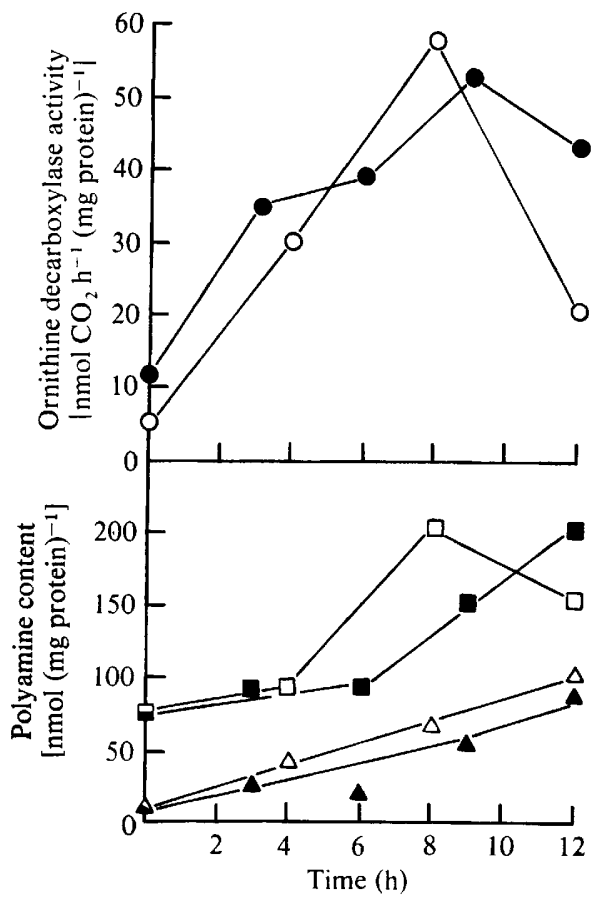

Fig. 1. Ornithine decarboxylase activity and polyamine content during germination and outgrowth of zoospores of strain E87 (open symbols) and strain 734 (filled symbols). At zero time, zoospores were induced to germinate by placing them in PYG broth and incubating at $28^{\circ} \mathrm{C}$. At the indicated intervals, samples of the culture were harvested and enzyme activity $(O, O)$, putrescine content $(\Delta, \Delta)$ and spermidine content $(\square, \square)$ were determined in extracts prepared as described in Methods.

\section{RESULTS}

\section{Ornithine decarboxylase in hyphae}

Achlya ornithine decarboxylase exhibited many properties in common with the enzyme from other fungi (Mitchell \& Rusch, 1973; Brawley \& Ferro, 1979; Aleksijevic et al., 1979; Inderlied et al., 1980) and higher eukaryotes (Janne \& Williams-Ashman, 1970, and references therein). Pyrixodal phosphate stimulated enzyme activity in crude extracts and the apparent $K_{\mathrm{m}}$ for the cofactor was $0.02 \mathrm{mM}$. The enzyme had a pH optimum of 7.2-7.6 and a $K_{\mathrm{m}}$ for ornithine of $0.148 \mathrm{mM}$. A reducing agent was required for optimum activity; therefore, dithiothreitol was included in the assay mixture and $\beta$-mercaptoethanol in the breakage buffer. Achlya ornithine decarboxylase was stable for at least 2 weeks at $-20^{\circ} \mathrm{C}$ when crude extracts were quickly frozen by submersion in a dry ice/methanol mixture (data not shown).

\section{Ornithine decarboxylase activity during zoospore germination}

The activity of ornithine decarboxylase was determined during germination and outgrowth of zoospores of Achlya. Dormant zoospores were induced to germinate by placing them in PYG broth at $28^{\circ} \mathrm{C}$. Enzyme activity increased over 3 -fold within the first $4 \mathrm{~h}$ of germination and attained maximal levels, approximately 5 - to 7 -fold above the activity determined in dormant zoospores at zero time, by $8 \mathrm{~h}$ (Fig. 1). During this period germ tubes emerged and rapidly elongated, as assessed by light microscopy. During the period between 8 and $12 \mathrm{~h}$ of outgrowth, enzyme activity declined at which time branching of germ tubes was evident.

Intracellular pools of putrescine and spermidine reflected increases in enzyme activity. At the time of maximal ornithine decarboxylase activity during germination, the putrescine content was approximately 5 -fold greater and the spermidine content $2 \cdot 5$-fold greater than in 


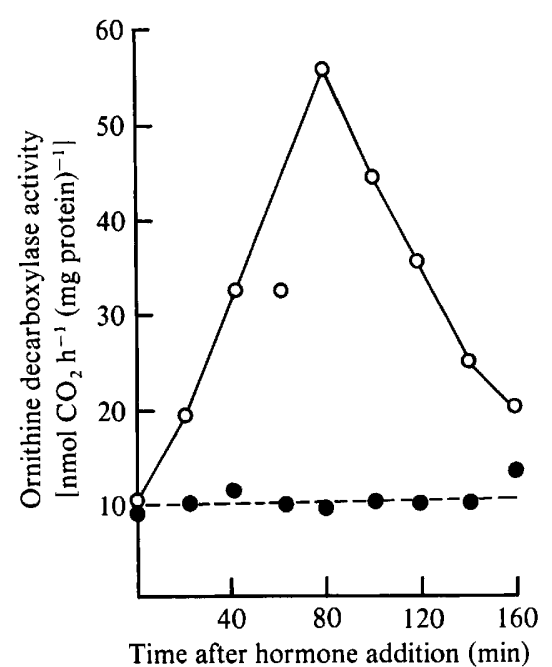

Fig. 2. Ornithine decarboxylase activity during hormone-induced sexual differentiation of mycelium of strain E87. At zero time, antheridiol was added to cultures (strain E87) previously grown for 17-18 h in enriched $(O)$ or minimal $(O)$ media. At the indicated intervals, samples of the culture were harvested and enzyme activity was determined in extracts prepared as described in Methods.

the dormant zoospores (Fig. 1). However, the intracellular pools of putrescine and spermidine continued to rise during the period between 8 and $12 \mathrm{~h}$ when ornithine decarboxylase activity decreased.

\section{Ornithine decarboxylase activity during hormone-induced differentiation}

Ornithine decarboxylase activity in mycelium cultured on enriched media (PYG broth or Emerson's medium) was stimulated $5 \cdot 2$-fold following addition of antheridiol to cultures (Fig. 2). The activity increased by $30 \mathrm{~min}$ and reached a maximum at $80 \mathrm{~min}$ after hormone addition. By $120 \mathrm{~min}$ after hormone addition enzyme activity had diminished to almost half the maximal level, and by $160 \mathrm{~min}$ the activity had decreased to about the level found in uninduced mycelium.

Changes in the intracellular pools of putrescine and spermidine correlated with the dramatic and transient rise in ornithine decarboxylase activity. By $90 \mathrm{~min}$ after hormone addition to cultures, putrescine and spermidine concentrations had increased approximately 5-fold and 4-fold, respectively, above the concentrations in uninduced mycelium (Fig. 3). Thereafter, the intracellular pools of the polyamines decreased rapidly, and by 150 min after hormone treatment the contents were the same as those determined in mature uninduced hyphae. At this time antheridial initials were visible by light microscopy and within $4 \mathrm{~h}$ following hormone induction numerous antheridia were present.

When mycelium cultured on a synthetic minimal medium (M-1) was induced to undergo sexual differentiation, antheridial initial formation progressed normally, as viewed by light microscopy, at a rate equivalent to that seen in PYG medium. Surprisingly, ornithine decarboxylase activity was not induced in these cultures nor was there a transient increase in accumulation of putrescine and spermidine (Figs 2 and 3).

Optimal concentrations of $\mathrm{Mg}^{2+}, \mathrm{Ca}^{2+}$ and $\mathrm{K}^{+}$have been cited as a requirement for induction of ornithine decarboxylase activity in certain eukaryotic systems (Costa \& Nye, 1978; Costa, 1979). We therefore determined the concentrations of the cations in PYG and M-1 media and found that $\mathrm{Ca}^{2+}$ and $\mathrm{Mg}^{2+}$ concentrations were 3 -fold greater and $\mathrm{K}^{+} 4$-fold greater in M-1 medium than in PYG broth. However, increasing the concentrations of $\mathrm{Ca}^{2+}$, $\mathrm{Mg}^{2+}$ and $\mathrm{K}^{+}$in PYG broth to those determined in $\mathrm{M}-1$ medium, in an attempt to block 

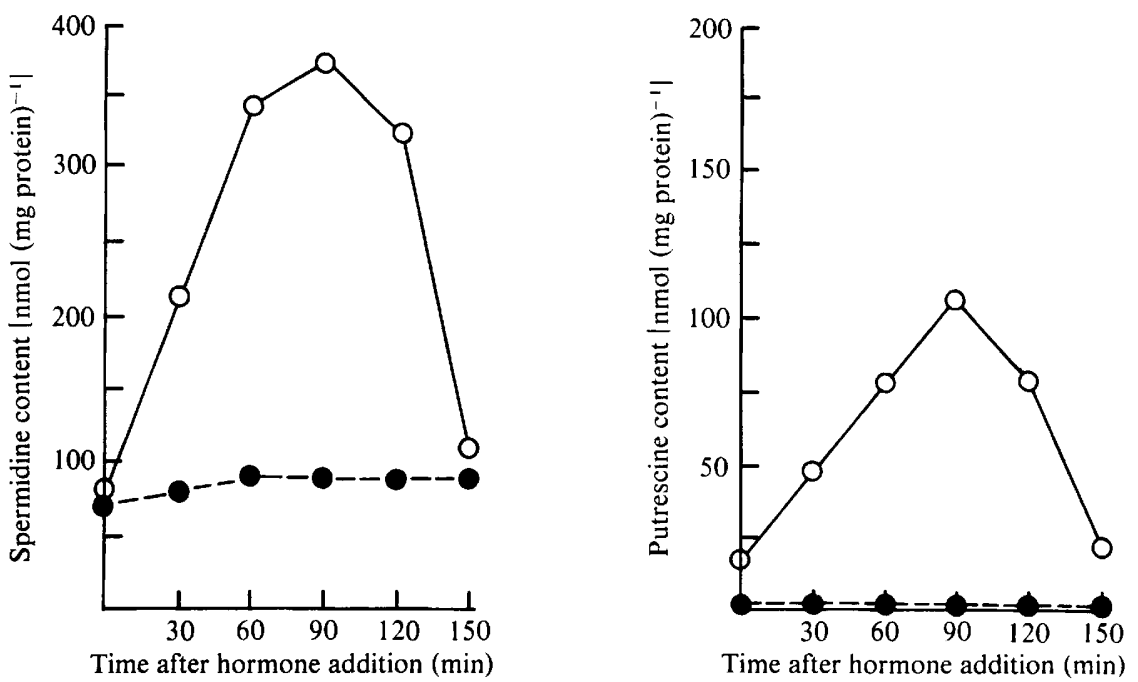

Fig. 3. Polyamine content during hormone-induced sexual differentiation of mycelium of strain E87. Experimental conditions were the same as described in the legend to Fig. 2. Cultures were grown in enriched $(O)$ or minimal $(O)$ media.

enzyme induction, had no effect on hormonal stimulation of ornithine decarboxylase. Any of several naturally occurring amino acids (alanine, asparagine, glutamine, glycine and serine) have been shown to be an essential requirement for the induction of ornithine decarboxylase in cultured Chinese hamster ovary cells maintained with a salt/glucose medium (Costa et al., 1980). However, even when M-1 minimal medium was supplemented with all 20 L-amino acids no hormonal induction of ornithine decarboxylase activity occurred in the minimal medium (data not shown).

\section{DISCUSSION}

During two distinctly different periods of morphological change in the life cycle of Achlya there is a rapid and large increase in ornithine decarboxylase activity. This activity is paralleled by an accumulation in the intracellular pools of putrescine and spermidine.

The transient increase in ornithine decarboxylase activity during germination of asexual spores of Achlya is consistent with the general observation of increased ornithine decarboxylase activity during early growth and differentiation (Janne et al., 1978). Increases in ornithine decarboxylase activity have been reported during germination of zoospores of Blastocladiella emersonii (Mennucci et al., 1975), spherules of Physarum polycephalum (Mitchell \& Rusch, 1973), ascospores of yeast (Brawley \& Ferro, 1979) and during the yeast-hyphae transition of Mucor racemosus (Inderlied et al., 1980). In Achlya, the increase in ornithine decarboxylase activity correlated with an increase in RNA and protein synthesis previously reported by MacLeod \& Horgen (1979) and preceded the stage at which germ tubes emerged. Although mycelial growth continued following branching of germ tubes $(8-12 \mathrm{~h})$ and intracellular pools of putrescine and spermidine continued to rise, ornithine decarboxylase activity declined. This lack of correlation between decreased ornithine decarboxylase activity and putrescine concentration has been observed in other eukaryotic systems (McCann et al., 1975; Maudsley et al., 1978).

The hormonal induction of ornithine decarboxylase activity in mycelium cultured on enriched media is characteristic of changes in ornithine decarboxylase activity following hormone stimulation in other eukaryotic systems (Janne et al., 1978). The most striking aspect of this study was the lack of induction of ornithine decarboxylase activity during 
hormone-induced differentiation of Achlya in minimal medium. The lack of enzyme induction, presumably, accounts for the lack of accumulation in the intracellular pools of putrescine and spermidine.

In a previous report, Michalski (1978) showed that there was a rapid increase in the rates of synthesis of ribosomal and total proteins following hormone treatment of mycelium cultured on M-1 medium. MacLeod \& Horgen (1979) have demonstrated that antheridiol stimulates total RNA and poly(A)-containing RNA as well as protein synthesis during hormone-induced differentiation of Achlya cultured on this minimal medium. A large amount of experimental data show a close correlation with ornithine decarboxylase and polyamine accumulation and macromolecular synthesis, and have generated confidence in the idea that the polyamines, and perhaps ornithine decarboxylase itself (Russell \& Durie, 1978), play an important role in cell proliferation and differentiation. Thus, the absence of polyamine accumulation and induction of ornithine decarboxylase during a period of elevated RNA and protein synthesis, such as sexual differentiation in Achlya, is atypical. Furthermore, it indicates that the rise in ornithine decarboxylase activity and the accumulation of putrescine and spermidine during hormone induction of $A$ chlya in enriched media are not essential for sexual differentiation.

Other instances in which macromolecular and polyamine synthesis have been uncoupled have been reported (Fillingame \& Morris, 1973; Harik et al., 1974; Newton \& Abdel-Monem, 1977 ) and undermine the notion that polyamines are essential for rapid cellular proliferation or differentiation.

This work was supported by Medical Research Council of Canada grants MA-6450 and MA-6116 to S.M.B. and C.J.M., respectively, and a summer studentship to W.P.G. from the Faculty of Medicine, Memorial University of Newfoundland. We acknowledge the excellent technical assistance of Alison Bullock and Anthony Metcalfe during preparation of large volumes of Achlya ambisexualis spore cysts.

\section{REFERENCES}

Aleksijevic, A., Grove, J. \& Schuber, F. (1979). Studies on polyamine biosynthesis in Euglena gracilis. Biochimica et biophysica acta 565, 199207.

BARksdale, A. W. (1969). Sexual hormones of Achlya and other fungi. Science 166, 831-837.

Boyle, S. M., Macintyre, M. F. \& Sells, B. H. (1977). Polyamine levels in Escherichia coli during nutritional shift-up and exponential growth. Biochimica et biophysica acta 477, 221-227.

Brawley, J. \& Ferro, A. J. (1979). Polyamine biosynthesis during germination of yeast ascospores. Journal of Bacteriology 140, 649-654.

Costa, M. (1979). The regulation of ornithine decarboxylase activity in intact normal and transformed cells maintained with a minimal salts/glucose medium. Life Sciences 25, 2113-2124.

CosTA, M. \& NYE, J. S. (1978). Calcium, asparagine and cAMP are required for ornithine decarboxylase activation in intact chinese hamster ovary cells. Biochemical and Biophysical Research Communications 85, 1156-1164.

Costa, M. Meloni, M. \& Jones, M. K. (1980). Regulation of ornithine decarboxylase activity by amino acids, cyclic AMP and luteinizing hormone in cultured mammalian cells. Biochimica et biophysica acta 608, 398-408.

EMERSON, R. (1958). Mycological organization. Mycologia 50, 589-621.

Fillingame, R. H. \& Morris, D. R. (1973). Polyamine accumulation during lymphocyte transforma- tion and its relation to the synthesis, processing, and accumulation of ribonucleic acid. Biochemistry 12 , 4479-4487.

Griffin, D. H. \& BREukeR, C. (1969). Ribonucleic acid synthesis during the differentiation of sporangia in the water mold Achlya. Journal of Bacteriology 98, 689-696.

Griffin, D. H., Timberlake, W. E. \& Cheney, J. C. (1974). Regulation of macromolecular synthesis, colony development, and specific growth rate of Achlya bisexualis during balanced growth. Journal of General Microbiology 80, 381-388.

Harik, S. I., Hollenberg, M. O. \& SNYder, S. H. (1974). $\alpha$-Hydrazino-ornithine blocks net synthesis of putrescine but not of RNA and DNA. Nature, London 249, 250-251.

Horgen, P. A., Smith, R., Silver, J. C. \& Craig, G. (1975). Hormonal stimulation of ribosomal RNA synthesis in Achlya ambisexualis. Canadian Journal of Biochemistry 53, 1341-1345.

Inderlied, C. B., Cihlar, R. L. \& Sypherd, P. S. (1980). Regulation of ornithine decarboxylase during morphogenesis of Mucor racemosus. Journal of Bacteriology 141, 699-706.

JANNE, J. \& Williams-AshmaN, H. G. (1970). Mammalian ornithine decarboxylase: activation and alteration of physical behaviour by thiol compounds. Biochemical Journal 119, 595-597.

Janne, J., Poso, H. \& RaInA, A. (1978). Polyamines in rapid growth and cancer. Biochimica et biophysica acta 473, 241-293. 
Macleod, H. \& Horgen, P. A. (1979). Germination of asexual spores of the aquatic fungus, Achlya bisexualis. Experimental Mycology 3, 70-82.

Maudsley, D. V., LeIf, J. \& KIND, J. J. (1978). Polyamine biosynthesis in serum-stimulated HeLa cells pulse-labelled with ${ }^{3} \mathrm{H}$-ornithine. In Advances in Polyamine Research, vol. 1, pp. 93-100. New York: Raven Press.

McCanN, P. P., TARdifF, C., Mamont, P. S. \& SHUBER, F. (1975). Regulation of ornithine decarboxylase by ornithine decarboxylase antizyme in HTC cells. Biochemical and Biophysical Research Communications 75, 948-954.

Mennucci, L., Rojas, S. \& Plessman Camargo, E. (1975). Polyamines and ornithine decarboxylase activity during growth and differentiation in Blastocladiella emersonii. Biochimica et biophysica acta 404, 249-256.

MichalsKI, C. J. (1978). Protein synthesis during hormone stimulation in the aquatic fungus, Achlya. Biochemical and Biophysical Research Communications 84, 417-427.

Mitchell, J. L. \& Rusch, H. P. (1973). Regulation of polyamine synthesis in Physarum polycephalum during growth and differentiation. Biochimica et biophysica acta 297, 503-516.

Newton, N. E. \& Abdel-Monem, M. M. (1977). Inhibitors of polyamine biosynthesis. 4. Effects of $\beta$-methyl- $( \pm)$-ornithine and methylglyoxal bis(guanylhydrazone) on growth and polyamine content of L1210 leukemic cells of mice. Journal of Medicinal Chemistry 20, 249-252.

Russell, D. H. \& DurIE, B. G. M. (1978). Activation of RNA polymerase I by ornithine decarboxylase. In Polyamines as Biochemical Markers of Normal and Malignant Growth, pp. 89-109. New York: Raven Press.

SchaffNer, W. \& Weissman, C. (1973). A rapid, sensitive and specific method for the determination of protein in dilute solution. Analytical Biochemistry 45, 502-514.

Silver, J. C. \& Horgen, P. A. (1974). Hormonal regulation of presumptive $\mathrm{mRNA}$ in the fungus Achlya ambisexualis. Nature, London 249, 252254.

TABOR, C. W. \& TABOR, H. (1976). 1,4-Diaminobutane (putrescine), spermidine and spermine. Annual Review of Biochemistry 45, 285-306.

Thomas, D. \& Mullins, J. T. (1967). Role of enzymatic wall softening in plant morphogenesis: hormonal induction in Achlya. Science 156, 84-85.

Thomas, D. \& Mullins, J. T. (1969). Cellulase induction and wall extension in the water mould Achlya ambisexualis. Physiologia plantarum 22, 347-353.

Timberlake, W. E. (1976). Alterations in RNA and protein synthesis associated with steroid hormone induced sexual morphogenesis in the water mould Achlya. Developmental Biology 51, 202-214. 